\title{
The Meaning of Caring in Nursing Practice
}

\section{Nancy D. Blasdell}

Rhode Island College School of Nursing, 600 Mt. Pleasant Avenue, Providence, RI 02908-1991, USA

\section{Introduction}

The dynamic essence of nursing is due to caring. Unfortunately, many different terms such as care, care-giving, care receiving, nursing care, etc. are used interchangeably which promotes confusion. Thus, the concept of care can be considered one of the least understood parts of nursing. It is important to note that because there are multiple ways to define caring from different paradigms, the frame of reference is imperative to understand the definition.

The purpose of this paper is to: analyze three conceptualizations of caring and discuss the relevance of incorporating theory into practice.

\section{Watson's Theory of Caring}

Watson [1] defines caring as: "the moral ideal of nursing whereby the end is protection, enhancement, and preservation of human dignity. Human caring involves values, a will and a commitment to care, knowledge, caring actions, and consequences. All of human caring is related to inter subjective human response to health-illness; environmental-personal interaction; a knowledge of the nurse caring process; self knowledge, knowledge of one's power and transaction limitations" (p. 901). Moreover, Watson posits that "the essence of the value of human care and caring may be futile unless it contributes to a philosophy of action. . . The actual concrete action of caring can transcend the value (and pass it on)... The value of caring is grounded in the self-transcending creative nurse" (p. 32). She further believes that human-to-human caring interactions of nursing cannot be validated or understood using a "positivistic, deterministic, materialistic mind set" [1.

Watson [1] acknowledges the differences between traditional science and human science. They are as follows:

\begin{tabular}{|c|c|}
\hline $\begin{array}{l}\text { Traditional Science } \\
\text { Context }\end{array}$ & Nursing Human Science for Caring \\
\hline Normative & Ipsative \\
\hline Reductionistic & Transactional \\
\hline Mechanistic & Metaphysical; Humanistic-contextual \\
\hline Method centered & Phenomena centered \\
\hline Disease centered on & Person-experience centered \\
\hline $\begin{array}{l}\text { Pathology-physiology, the } \\
\text { physical body }\end{array}$ & $\begin{array}{l}\text { Human responses to illness and } \\
\text { personal meanings of human condition }\end{array}$ \\
\hline Ethics of 'science' & Human-social ethics- morality \\
\hline More quantitative & More qualitative \\
\hline Absolutes, givens, laws & Relativism, probabilism \\
\hline Human as object & Human as subject \\
\hline Objective experiences & Subjective-intersubjective experiences \\
\hline Facts & Experience, meaning \\
\hline Nomothetic & Idiographic + / nomethic \\
\hline Concrete-observable & Abstract- may or may not "be seen" \\
\hline
\end{tabular}

\section{Publication History:}

Received: December 16, 2016

Accepted: May 22, 2017

Published: May 24, 2017

\section{Keywords:}

Nursing practice, Caring, knowledge

\begin{tabular}{l|l} 
Analytical & $\begin{array}{l}\text { Dialectical, philosophical, } \\
\text { metaphysical } \\
\text { Science as creative process of } \\
\text { discovery }\end{array}$ \\
Science as product & $\begin{array}{l}\text { Human = mind/body/spirit gestalt } \\
\text { of whole being (not only more } \\
\text { than sum of parts, but different) } \\
\text { (bio-psycho-socio-cultural- } \\
\text { spiritual-being) } \\
\text { 'Real' is that which is } \\
\text { measurable, observable, and } \\
\text { knowable }\end{array}$ \\
$\begin{array}{l}\text { 'Real' is abstract, largely subjective } \\
\text { as well as objective, but is may } \\
\text { or may not ever be fully known, } \\
\text { observable, fully measured, } \\
\text { what is 'real' holds mystery and } \\
\text { unknowns yet to be discovered }\end{array}$
\end{tabular}

A nurse is required to perform certain acts for her patient which are legally and ethically binding. Watson [1] posits that the value of human care and caring is more than the mere action of performance. Caring involves a sense of self identity and spirit of the person. It involves a pure sense of dedication and commitment to the patient. A specific action of caring may transcend the value because it is "grounded in the self-transcending creative nurse" [1].

The following are Watson's [1] eleven assumptions related to Human Care Values in Nursing:

1. Care and love are the most universal, the most tremendous, and the most mysterious of cosmic forces: they comprise the primal and universal psychic energy.

2. Often these needs are overlooked; or we know people need each other in loving and caring ways, but often we do not behave well toward each other. If our humaness is to survive, however, we need to become more caring and loving to nourish our humanity and evolve as a civilization and live together.

3. Since nursing is a caring profession, its ability to sustain its caring ideal and ideology in practice will affect the human development of civilization and determine nursing's contribution to society.

"Corresponding Author: Dr. Nancy D. Blasdell , Rhode Island College School of Nursing, 600 Mt. Pleasant Avenue, Providence, RI 02908-1991, USA ; E-mail: nblasdell@ric.edu

Citation: Blasdell ND (2017) The Meaning of Caring in Nursing Practice. Int $\mathrm{J}$ Nurs Clin Pract 4: 238. doi: https://doi.org/10.15344/2394-4978/2017/238

Copyright: @ 2017 Blasdell. This is an open-access article distributed under the terms of the Creative Commons Attribution License, which permits unrestricted use, distribution, and reproduction in any medium, provided the original author and source are credited. 
1. As a beginning we have to impose our own will to care and love upon our own behavior and not on others. We have to treat ourselves with gentleness and dignity before we can respect and care for others with gentleness and dignity.

2. Nursing has always held a human-care and caring stance in regard to people with health-illness concerns.

3. Caring is the essence of nursing and the most central and unifying focus for nursing practice.

4. Human care, at the individual and group level, has received less and less emphasis in the health care delivery system.

5. Caring values of nurses and nursing have been submerged. Nursing and society are, therefore, in a critical situation today in sustaining human care ideals and a caring ideology in practice. The human care role is threatened by increased medical technology, bureaucratic-managerial institutional constraints in a nuclear age society. At the same time there has been a proliferation of curing and radical treatment cure techniques often without regard to costs.

6. Preservation and advancement of human care as both an epistemic and clinical endeavor is a significant issue for nursing today and in the future.

7. Human care can be effectively demonstrated and practiced only interpersonally. The intersubjective human process keeps alive a common sense of humanity; it teaches us how to be human by identifying ourselves with others, whereby the humanity of one is reflected in the other.

8. Nursing's social, moral, and scientific contributions to humankind and society lie in its commitment to human care ideals in theory, practice, and research (p. 32, 33).

The eleven assumptions to Human Care Values in Nursing provide an understanding of how nursing is connected to caring. The assumptions give a sense of purpose to the concept of caring from Watson's perspective.

In order to understand nursing as the science of caring, Watson derived 10 primary carative factors. The carative factors involve the interpersonal aspects of caring and function as structural guides to understand care as a phenomenon in an interpersonal relationship process. The carative factors and processes are linked to basic human needs, human relationships, and health maintenance [2]. They are as follows:

1. The formation of a humanistic-altruistic system of values

2. The instillation of faith-hope

3. The cultivation of sensitivity to one's self and to others

4. The development of a helping-trust relationship

5. The promotion and acceptance of the expression of positive and negative feelings

6. The systematic use of the scientific problem-solving method for decision making

7. The promotion of interpersonal teaching-learning

8. The provision for a supportive, protective, and (or) corrective mental, physical, sociocultural, and spiritual environment

9. Assistance with the gratification of human needs

10. The allowance for existential-phenomenological forces (p. 9, 10).
Watson [3] explains that the carative factors refer to how interventions are associated to the human care process. As the nurse has interaction with the patient, the carative factors become actualized. She further explains that higher levels of caring can occur between different nurses and different experiences.

The nurse-patient transpersonal dimension is part of the dynamics of the human caring process [3]. "An event, such as an actual occasion of human care, is a focal point in space and time from which experience and perception are taking place, but the actual occasion of caring has a field of its own that is greater than the occasion itself" (p.59). The actual caring occasion as it is called, includes action and choice by the patient and the nurse. The experience of coming together in a caring situation provides the two people the opportunity to formulate a decision of "how to be in the relationship - what to do in the moment" [3].

Watson's Theory of Human Care involves three major areas:

1. Nursing within the context of human science and art;

2. Mutuality of person/self of both nurse and patient with mindbody-soul gestalt, within a context of intersubjectivity;

3. the moral ideal of the human care relationship in nursing which includes concepts such as phenomenal field, actual caring occasion, and transpersonal caring [3].

The actual goals of the theory are related to the mental and spiritual growth for oneself and others, discovering meaning in one's own existence and experiences, discovering inner power and control, and enhancing occurrences of transcendence and self-healing [3]. The actual agent of change is considered the patient. However, the nurse can be a co-participant in the change through the process of human care. The agent of change is the "personal, internal mental-spiritual mechanisms of the person who allows the self to be healed through various internal or external means, or without external agents, but through an inter-subjective interdependent process wherein both persons may transcend self and usual experiences" [3].

The interventions of Watson's Human Care Theory are associated to the human care process with complete participation of the nurse/ person in conjunction with the patient/person. These interventions require an intention, a drive, a relationship, and actions. The process requires a commitment to caring as a moral obligation directed toward the preservation of humanity [3]. The carative factor, as mentioned earlier, is formulated by a knowledge base and clinical competence. It is only when the nurse is being with the other person can the carative factors become actualized.

It is important to remember that the perspective of Watson's Theory of Human Care is spiritual-existential and phenomenological in its orientation. However, it has also been influenced by Eastern Philosophy [3]. The context is humanitarian and metaphysical and incorporates the art and science of nursing. Science is emphasized in the context of human science [3].

\section{Leininger Theory of Caring}

Madeleine Leininger is known world wide as the founder of transcultural nursing. She developed her thoughts during the middle 1950's. When she worked as a psychiatric nurse specialist in a child guidance home, she was exposed to children from many diverse 
cultural backgrounds. She discovered that the staff had a lack of understanding of how cultural backgrounds affected the behavior of the children. Therefore, she realized that there was a need to develop strategies in incorporate diversified cultures, patterns, and lifestyles [4]. She therefore, pursued her doctoral study with a concentration on cultural anthropology. While completing her schooling, she gained an understanding of the importance of providing care within a cultural context. She began to adapt specific concepts and themes from anthropology in order to pursue the Theory of Transcultural Care [4]. Leininger [5] defines caring as "Caring in the generic sense refers to those assistive, supportive, or facilitative acts towards or for another individual or group with evident or anticipated needs to ameliorate or improve a human condition or lifeway..." (p. 900). Leininger separates the generic sense of caring from professional caring. According to Leininger, professional caring is considered "those cognitive and culturally learned behaviors, techniques, processes, or patterns that enable or help an individual, family, or community to improve or maintain a favorable healthy condition or lifeway" [6].

\section{Leininger [6] has the following assumptions about human caring:}

1. Human caring is a universal phenomenon, but the expressions, processes and patterns vary among cultures.

2. Every nursing care situation has transcultural caring behaviours, needs and implications.

3. Caring acts and processes are essential for human development, growth and survival.

4. Caring should be considered the essence and unifying intellectual and practice dimension of professional nursing.

5. Caring has biophysical, psychological, cultural, social and environmental dimensions which can be studied and practised to provide holistic care to people.

6. Transcultural caring behaviours, forms and processes have yet to be verified from diverse cultures; when this body of knowledge is procured, it has the potential to revolutionize present-day nursing practices.

7. To provide therapeutic nursing care, the nurse should have the knowledge of caring values, beliefs and practices of the client (s).

8. Caring behaviours and functions vary with social structure features of any designed culture.

9. The identification of universal and non-universal folk and professional caring behaviours, beliefs and practices will be important to advance the body of nursing knowledge.

10. Differences exist between the essence and essential features of caring and curing behaviours and processes.

11. There can be no curing without caring but there may be caring without curing (p.901).

\section{Critical analysis of Watson and Leininger Theories of Caring}

Although Watson and Leininger are highly respected for their theories on caring, they view caring from two different perspectives. Only by understanding their philosophical underpinnings, epistemology, and constructs from which they are coming from can one fully understand and appreciate their perspectives.

As a common theme, both Watson and Leininger view nursing "as a humanistic science, with the concept of caring being the central unifying domain of nursing" [4]. However, both theorists formulated a different picture of caring. Watson concentrates on the philosophic (existential-phenomenological) and spiritual foundation of caring and believes caring to be "the ethical and moral ideal of nursing" [4]. Whereas Leininger places caring in a cultural context because caring patterns can differ transculturally [4].

Each of the theorists educational background played a significant role in their theory development. In 1973, Watson completed her doctoral degree in educational psychology from the University of Colorado. She had a strong connection with the humanist Carl Rogers regarding her concentration on the interpersonal and transpersonal processes in human care.

Leininger completed her doctoral study at the University of Washington in which she concentrated on cultural anthropology. For two years she lived with the residents of New Guinea in order to conduct an ethno-nursing and ethnographic research study of two villages [4]. This work provided an enlightenment for her which showed that "care and beliefs about health and illness are imbedded in the values, world views and life patterns of people" (p. 900). This new discovery enabled her to construct the theory of transcultural care.

Leininger and Watson differ on whether there is a difference between generic caring and professional caring. Watson [1] believes that caring is an interpersonal process between two people with transpersonal dimensions. "Transpersonal caring, an important component of caring, occurs when the nurse detects the subjective world of the patient, experiences union with it and expresses the union in such a way that both experience a freeing from isolation. Transpersonal caring, then, is a spiritual space, and life history of each other. This transcendence allows both the patient and the nurse to enter the phenomenal field of the other" [4].

Leininger separates generic caring from professional caring. For example, she views professional caring as behaviors which are learned cognitively and culturally derived, techniques, processes, or patterns which help an individual, family, or community to improve or maintain a healthy condition or life pattern [4]. Central to Leininger's Transcultural Theory of Nursing is the key element that "human caring is a universal phenomenon, but the expressions, processes, and patterns vary among cultures... caring has biophysical, psychological, cultural, social, and environmental dimensions which can be studied and practiced to provide holistic care to people" [4]. The anthropological foundation infers that the social, cultural, and historical context of human beings is included. Leininger posits that human beings cannot exist away from their cultural background and social structures.

Another important component of Leininger's theory is that there is wide applicability due to the fact that theory generation may occur at multiple levels (macro range, middle range, and micro range). Therefore, the researcher may decide where to enter and leave the model. Leininger [6]] classified a number of her constructs into taxonomy. The purpose of developing the taxonomy was to assist the nurses in conceptualizing, ordering, and studying different types of caring phenomena. Leininger's theory is considered to be the only one which combines theory and method and defines different levels of abstraction and methodological approaches [4].

Leininger disagrees that nursing should be included in the metaparadigm of person, environment, health, and nursing. Instead, she believes that care should be one of the concepts because she 
Page 4 of 5

thinks it is central and a unifying focus for nursing. She also views nursing as being both humanistic and scientific caring [5]. Although caring is not unique to the nursing discipline, the specificity and goal of nursing focuses around caring for people in a manner that is congruent with their culture, values, lifeways and patterns. She defines nursing as a "learned humanistic art and science that focuses upon personalized care behaviors, functions and processes directed toward promoting and maintaining health behaviors or recovery from illness" [4]. She stresses that the focus of nursing could be the individual, families, culture or society as a whole.

Watson on the other hand, views nursing as both a human science and an art activity. The context of human science for nursing is derived from:

1. a philosophy of human freedom, choice and responsibility

2. a biology and psychology of holism (non-reducible persons interconnected with other and nature

3. an epistemology that allows not only for empirics, but for advancement of aesthetics, ethical values, intuition and process discovery

4. an ontology of time and space

5. a context of interhuman events, processes and relationships

6. a scientific world view that is open [4].

Watson [1] believes that the activity of the art of nursing is concentrated of the transpersonal caring relationship. Watson states that "It is art when the nurse, having experienced or realized the feelings of another, is able to detect and sense those feelings and in turn is able to express them in such a way that the other person is able to experience them more fully and release the feelings he or she has been longing to release... Nursing is defined as a human science of person and human health-illness experiences that are mediated by professional, personal, scientific, aesthetic, and ethical human transactions" [1]. "Caring is based on a guiding force and value system that affect the encounters between the nurse and other persons. Whether or not one is conscious of one's philosophy and values, they affect one's caring behavior. Humanistic values and altruistic behavior can be developed through consciousness raising and a close examination of one's views, beliefs, and values. They can be further developed through experiences with different cultures, early experiences that have aroused compassion and other emotions, study of the humanities, literary and artistic experiences, value-clarification exercises, and personal growth experiences" [1].

\section{Leininger Theory of Caring}

Swanson [7] describes caring as " a nurturing way of relating to a valued other toward whom one feels a personal sense of commitment and responsibility" ( p. 354). It is considered a middle range theory which is empirically succumbed to phenomenological inquiry. Although this theory originated from perinatal contexts, there are citings in nursing and non-nursing literature which postulate that the theory of caring may have generalizability beyond the context of perinatal and nursing practice [7]. She also identifies five categories which include: maintaining belief, knowing, being with, doing for, and enabling. Swanson [7] confesses that a limitation of her original caring theory was that it did not have the structure to demonstrate how the five categories related to each other. Therefore, she worked on correcting this limitation.
Swanson [8] believes that there are assumptions regarding the four main phenomena of concern to nursing: persons/clients, health/wellbeing, environments and nursing. Swanson [8] agrees with Watson [6] in that the way in which nurses identify persons and personhood plays a role in identifying the clients of nursing and what defines the practices, environments, and goals of nursing care. The individual's life experience is influenced by the genetic makeup, spiritual enrichment, and the capacity to portray free will. Individuals are not stagnant in regards to their wholeness, but instead are involved in "becoming, growing, self-reflecting, and seeking to connect with others" [8].

Environment is defined according to the specific situation [8]. In nursing, it is considered any particular context which has influence or is influenced by the patient. The amount of influence is considered multi-faceted which includes; biophysical, psychological, cultural, political, economic, social, and spiritual [8]. It is important to note that the environment of the patient could perhaps be even more specified in which the environment may be considered the organs or tissues of the body [8].

Health/Well-being can be present in an individual by experiencing wholeness [8]. Wholeness is "a sense of integration and becoming wherein all facets of being are free to be expressed. Facets of being include the many selves that make us human: our spirituality, thoughts, feelings, intelligence, creativity, relatedness, femininity, masculinity and sexuality to name just a few. Healing, the process of reestablishing well-being, includes releasing inner pain, establishing new meanings, restoring integration and emerging into a sense of renewed wholeness" [8].

Nursing is frequently viewed as an extension of medicine focusing on psychomotor skills and a willingness to follow orders [8]. Unfortunately, our society places a higher priority on stopping the disease and circumventing death than on the prevention of health problems, enhancement of the quality of life, and maintaining a patient's dignity [8]. The beauty of nursing can be seen by those who truly have an appreciation for nursing. This can be accomplished by either being a recipient of high quality nursing, receiving formal education, or observing exceptional clinical practice [8].

Swanson [8] believes that nursing includes "therapeutic practices ... (in which) the nurses are grounded in knowledge of nursing, related sciences, and the humanities, as well personal insight and experiential understanding and that the goal of nurse caring is to enhance the well-being of its recipients. It is the blend of knowledge/information and the goal of practice that distinguishes nursing from others whose practices includes caring" (p. 354).

Swanson [8] posits that there are five caring processes which relate to each other. These include: maintaining belief, knowing, being with, doing for, and enabling. Each of these processes has a unique function of relating to the theory of caring.

Maintaining belief is considered to be the fundamental belief in which persons have the capability to progress through transitions and life events and look towards the future with meaning [8]. Nurses approach the patient with the idea that the medical condition or developmental challenge has a personal meaning to the patient. Maintaining belief is also the foundation of nursing practice. It allows for having faith to progress through life's events, transitions, and gives the ability to perceive the future with meaning that starts or maintains caring [8]. This foundation provides the opportunity to accelerate 
Page 5 of 5

nursing in serving the humanity through commitment. On the societal level, maintaining belief is considered to be involved in the person's right to get through experiences and focus on a future with meaning that provides motivation to nurses regarding political activism in areas such as access to care and the necessity for health care reform [8]. On the interpersonal level, the nurse provides her patient and/or family with physical and emotional safety in order to support them through the stressful experience.

Swanson [8] believes that "knowing is the anchor that moors the beliefs of nurses/nursing to the lived realities of those served" (p. 355). Knowing tries to provide justification for events because it has meaning in life. Only through the enhancement of ethical, aesthetic, and empirical knowledge can the essence of caring be known as therapeutic [8]. Nurses must "know thy self" in order to truly understand another person's reality and to fully appreciate the capacity one may focus on the patient's lived reality [8].

The term "being with" involves emotionally connecting with the patient. Patients benefit from this term because they feel that they are appreciated and are connected with their nurses. In addition to physical presence, "being with" also means the ability to provide availability and the ability to endure with the patient. It is the feeling of connectedness that comforts the patient. Nurses accomplish this by spending time with their patients, having an "authentic presence, attentive listening and contingent reflective responses" [8].

\section{Relevance of Incorporating Theory Into Practice}

Argyris and Schon [9] state that "we cannot learn what someone's theory-in-use is simply by asking him. We must construct his theoryin-use from observations of his behavior (p. 7). Argyris and Schon [9] also state that "The most important kind of consistency lies not between propositions in the theory... but among the governing variables of the theory that are related to assumptions about self, others, and the behavioral setting" (p. 20, 21).

"The relevance of basic theory to practical competence can be determined only through the intermediary of theory of practice, because basic theory comes to bear on action only through the light it throws on the assumptions underlying theory of practice" [9]. McFarlane [10] states that "Nursing is a practice discipline and therefore, any theory of nursing must be intimately related to this practice. Theory grows out of practice.... The purpose of practice theory is to be able to make a prescription for practice where, after all, nursing begins and ends" (p. 264).

According to Argyris, Putnam, and Smith [9] "action science is an inquiry into how human beings design and implement action in relation to one another... Action science call for basic research and theory building that are ultimately related to social intervention" (p. 4). It is through reflecting on our practice and relating it to other literatures, including those of the philosophy of science and social inquiry, that we hope to articulate an action science" [9].

\section{Conclusion}

Caring constitutes a variety of meanings. Most scholars view caring from their own context and therefore, a universal definition is not possible. The complexity of defining caring should be left up to the individual. It is only when we understand ourselves that we can formulate our own definition of caring. Providing an intellectual dialog on caring within the nursing community will enable the nursing profession to grow at its fullest potential by strengthening the core of the nurse for his/her fullest potential as a practicing nurse.

\section{Conclusion}

Caring constitutes a variety of meanings. Most scholars view caring from their own context and therefore, a universal definition is not possible. The complexity of defining caring should be left up to the individual. It is only when we understand ourselves that we can formulate our own definition of caring. Providing an intellectual dialog on caring within the nursing community will enable the nursing profession to grow at its fullest potential by strengthening the core of the nurse for his/her fullest potential as a practicing nurse.

\section{Competing Interests}

The authors declare that they have no competing interests.

\section{References}

1. Watson J (1988) Nursing: Human science and human care. New York, NY: National League for Nursing.

2. Watson J (1979) Nursing: the philosophy of science and caring. Boston, MA: Little, Brown, and Company.

3. Watson J (1985) Nursing: human science and health care. Menlo Park, CA: Appleton-Century Crofts.

4. Cohen J (1991) Two portraits of caring: a comparison of the artists, Leininger and Watson. Journal of advanced nursing 16: 899-909.

5. Leininger M (1988b) The phenomenon of caring: importance, research questions, and theoretical considerations, In qualitative research methods in nursing, Orlando, FL: Grune and Stratton.

6. Leininger M (1985) Ethnography and ethnonursing: models and modes of qualitative data analysis. In qualitiative research methods in nursing. Orlando, FL: Grune \& Stratton.

7. Swanson K (1991). Empirical development of a middle range theory of caring, Nursing Research, May/June 40: 161-165.

8. Swanson K (1993) IMAGE: Journal of nursing scholarship 25: 352-357.

9. Argyris C, Schon D (1974) Theory in practice: increasing professional effectiveness, San Francisco, CA: Jossey-Bass Publishers.

10. McFarlane $\mathrm{J}$ (1976) A charter of caring. Journal of advanced nursing 1 : 187-196. 